\title{
RESEÑA
}

López Palomeque, Francisco y Plaza Gutiérrez, Juan Ignacio (2019): Geografía de Europa. Estructuras, procesos y dinámicas territoriales. Editorial Tirant Humanidades, UVP. Valencia, 589 pp. ISBN 978-84-17508-33-3.

\section{Título: Conocer y pensar la nueva geografía de Europa}

La enseñanza universitaria ha estado desde siempre auxiliada y necesitada de libros orientados a servir de apoyo al profesorado y de guía para el alumnado, toda vez que el compendio de saberes fundamentales de una disciplina, articulados con un propósito académico, y a la vez didáctico, de sus fundamentos, procesos y evolución, no se suple con otras herramientas o recursos al servicio de la enseñanza y aprendizaje de la misma. Los manuales no pasan de moda como recurso, aunque se puedan quedar desfasados y se precisen nuevas ediciones y nuevos textos que se hagan eco de los cambios en cada disciplina o especialidad. Estas obras evolucionan al compás que lo hacen el saber y el conocimiento científico que es preciso llevar a las aulas y transmitir a los estudiantes en forma de materias o asignaturas, las cuales a su vez están sometidas a un permanente proceso de revisión y actualización de contenidos y programación. Todos los universitarios hemos agradecido en su momento un buen manual para estudiar y profundizar las explicaciones recibidas en clase y también, para llegado el momento del examen (por qué no decirlo), contar con la seguridad de disponer de un riguroso y recomendado libro general de referencia. Y esto no ha cambiado con el paso de los años, ni con el advenimiento de las nuevas tecnologías y las redes sociales, que ponen a disposición de todos, profesorado y alumnado, un ingente volumen de información que es preciso transformar en conocimiento teórico y aplicado.

De ahí que siga siendo una buena noticia la publicación de manuales actualizados que revisan y ponen al día los contenidos y enfoques que son pertinentes en cada etapa curricular de las enseñanzas universitarias. Esta es la naturaleza del libro que nos ocupa sobre Geografía de Europa, recién publicado por la editorial valenciana Tirant Humanidades. Una obra coral, ambiciosa, bien estructurada y de contenidos sustanciales sobre los más variados aspectos de 
la geografía física y humana del continente europeo que aparece coordinada y editada por los profesores Francisco López Palomeque, de la Universidad de Barcelona, y Juan Ignacio Plaza Gutiérrez, de la Universidad de Salamanca.

La oportunidad de este libro deriva, en primer lugar, del hecho de que son escasos los textos de esta naturaleza sobre Europa y su realidad política, social, medioambiental y económica en el contexto de la globalización y en las coordenadas geopolíticas de un mundo cambiante y convulso, observado por los profesionales de la geografía con profunda curiosidad y ojo crítico. También es una obra oportuna por el enfoque general adoptado, muy integrador y sintético de una realidad compleja y sometida a frecuentes tensiones, donde se plantean problemas y se buscan respuestas a los desafíos de la Europa actual, tanto en el ámbito de sus estructuras físicas y paisajes naturales, como en términos demográficos, urbanos y rurales, y en relación con las transformaciones geoeconómicas actuales, que perfilan una economía europea altamente terciarizada y un marco político-geográfico que gira en torno a la Unión Europea y sus retos.

La mayor novedad de esta Geografía de Europa estriba en la superación de los enfoques descriptivos y la propuesta de una obra profundamente analítica, muy coherente en los aspectos conceptuales. Por ejemplo: la idea de Europa y sus límites convencionales se conjuga sin titubeos con la construcción de la superestructura política que es la Unión Europea; los elementos básicos del análisis territorial -medio físico, población, espacios urbano y rural, actividades económicas y realidad política- forman un único cuerpo articulado con armonía y solidez en todas sus partes, a la vez que es posible la lectura autónoma de cada una de ellas; y la visión de Europa como un espacio político-territorial diverso, plural y en mutación constante recorre toda la obra. La misma está articulada con fluidez en ocho capítulos que dan cuenta de las estructuras, hechos, procesos y dinámicas que permiten comprender la esencia de la geografía de Europa en el segundo decenio del siglo XXI, sin obviar conflictos, riesgos y desafíos.

El libro es el resultado de un esfuerzo colectivo (los manuales clásicos son más obra de una sola firma, antes eran las enciclopedias las que reunían a nutridos equipos de expertos) que se sustancia en un elenco de autores, catorce en total, que representan bien a la universidad española y sus departamentos de Geografía, y que son, cada cual en la especialidad a la que se adscriben su docencia y su labor investigadora y producción científica, voces autorizadas y relevantes en la Geografía actual, con una trayectoria profesional muy solvente y con la audacia intelectual que se precisa para formular contenidos rigurosos a la vez que didácticos y, en cierto modo, retadores. Aquí corresponde subrayar el acertado papel que cabe atribuir a los dos coordinadores del libro, López Palomeque y Plaza Gutiérrez, que han sabido dar con el tono y el enfoque adecuados para amalgamar todos los ingredientes de este magnífico e imprescindible manual, seleccionar los contenidos, secuenciar los capítulos y reunir a los expertos que los firman. El resultado es una obra que condensa en clave contemporánea la 
idea de Europa como concepto geográfico, fruto, como se puede leer en su introducción, de una dialéctica histórica y actual del medio físico y de la sociedad humana.

Por último, los contenidos de la obra son de alto valor académico y rigor científico, aptos para los últimos cursos de títulos de Grado y también para nivel de Máster. El resultado entre capítulos es homogéneo y entre todos aportan una visión original y actualizada de la Europa de hoy. Sin duda, la Geografía está de enhorabuena con esta novedad bibliográfica a la que no es arriesgado augurar una entusiasta acogida por parte de docentes, estudiantes y amantes del saber en general

PAZ BENITO DEL POZO

Departamento de Geografía y Geología Universidad de León Fecha de recepción: 3/9/19. Fecha de aceptación: 9/11/19. 
